\title{
MEGA-RASGOS GEOMORFOLÓGICOS DEL MODELO DE ELEVACIÓN DIGITAL, ASOCIADOS AL VOLCAN BARVA
}

\author{
Luis Gmo. Obando A. \\ Escuela Centroamericana de Geología, Apdo 214-2060. UCR. \\ E-mail: lobando@geologia.ucr.ac.cr
}

(Recibido 14/2/05; Aceptado 17/3/05)

\begin{abstract}
The digital-elevation model have been made using the topographic map. The model shows following mega-features 1) Gentle denudational slopes, located towards south and west of Barva volcano. The drainage pattern is radial and this mega-feature is formed by recent pyroclastics that overlays lava flows. 2) Strong denudational slopes, located towards east of Barva volcano, the drainage pattern is radial and parallel and the topography is abrupt and eroded, probably ancient, formed by a possible debris avalanche. Another mega-feature is Alajuela Fault, a inverse fault that produced a recumbent fold. This fold is represented by a high scarp. Keywords: Barva volcano, Costa Rica, digital elevation model, mega-features, debris avalanche.

RESUMEN: El modelo de elevación digital a partir del mapa topográfico mostró mega-rasgos que geomorfológicamente corresponden con las siguientes tipos de laderas: 1) Laderas denudacionales de topografía suavizada hacia el sur y oeste del volcán Barva, las cuales tienen un patrón de drenaje radial, un extenso campo de piroclastos recientes los cuales recubren coladas de lavas. 2) Laderas denudacionales de topografía abrupta y escarpada hacia el este de dicho volcán, formadas en depósitos de avalancha (debris avalanche) y cortadas por drenajes de tipo radial y paralelo. En este modelo, es notoro la Falla de Alajuela, una falla inversa que genera un pliegue volcado representado por un fuerte escarpe de dirección grosea este-oeste.

Palabras clave: Volcán Barva, Costa Rica, modelo de elevación digital, mega-rasgos, depósitos de avalancha.
\end{abstract}

\section{INTRODUCCIÓN}

La presente investigación muestra, a partir del modelo de elevación tridimensional, rasgos geomorfológicos megascópicos asociados al flanco Sur del macizo del volcán Barva. El modelo de elevación fue creado a partir del mapa topográfico a escala 1 : 50000 (hoja Barva), con curvas de nivel cada $20 \mathrm{~m}$, utilizando el método conocido como red triangulada irregular o "triangulated irregular net- work (TIN)". La calibración y comprobación de campo tanto topográfica como geológica, fue realizada para la mayoría del área modelada. Para la zona con topografía abrupta que abarca el costado este del macizo del Barva, la cual es una zona de selva virgen abundate, no se realizó comprobación topográfica, excepto a lo largo de la carretera que conduce de San José a Guápiles. Los datos litológicos fueron tomadas de la literatura existente, por ejemplo Alvarado (2000), Pérez (2000) y Soto (1994). 


\section{MEGA-RASGOS GEOMÓRFICOS}

A partir del modelo tridimensional (Fig. 1a y b), es fácil notar como la topografía muestra dos mega-rasgos principales: Laderas denudacionales de topografía suavizada hacia el sur y oeste del volcán Barva y laderas denudacionales de topografía abrupta y escarpada hacia el este.

\section{Laderas Denudacionales de Topografía Suavizada:}

Son laderas que conforman el flanco sur y oeste del macizo del Volcán Barva; presentan una topografía relativamente suave, disectada por los colectores principales. En estas laderas, el desarrollo urbano es importante. Los cultivos

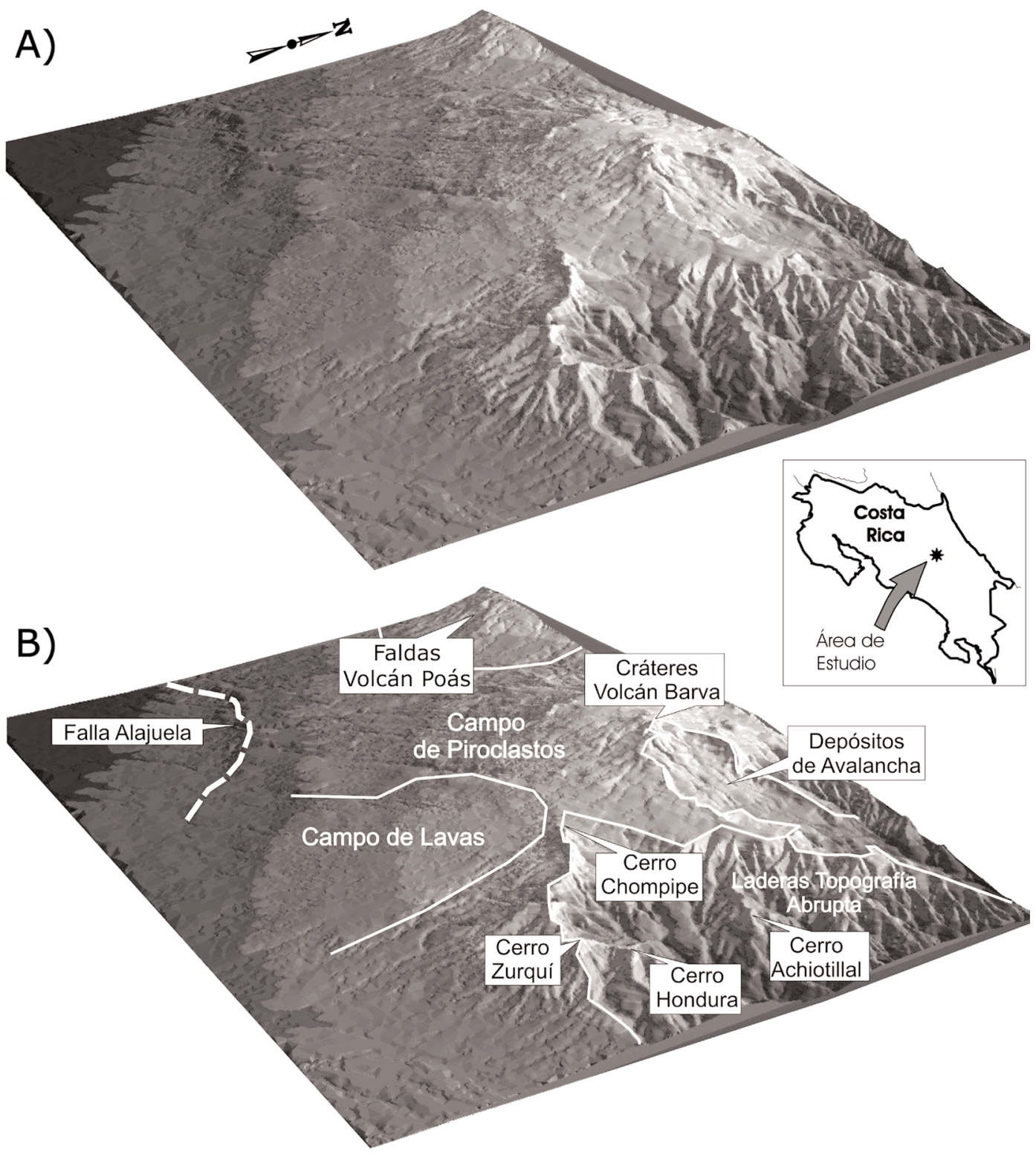

Fig. 1: Modelo de elevación del terreno. Flanco sur del macizo del volcán Barva. 
más relevantes son café y en las partes más altas se desarrolla al actividad pecuaria. En la cima del macizo, se ha creado el Área de Conservación de la Cordillera Volcánica Central (Parque Nacional Braulio Carrillo y la Reserva Forestal Cordillera Volcánica Central), cubierto por una selva densa de bosque primario.

En este mega-rasgo se pueden observar los siguientes sub-rasgos asociados:

\section{Patrón de drenaje radial}

Representado por líneas relativamente rectas de dirección recurrente noreste-suroeste a partir del centro de emisión volcánica (cráteres volcán Barva). Estos rasgos lineales corresponden con los ríos principales como Tambor, Itiquís, Alajuela, Guararí y Ciruelas. Los procesos erosivos han hecho que estos drenajes generen profundos cañones de pendiente elevada, los cuales se hacen más profundos hacia la cima del volcán Barva, debido a la erosión persistente de las capas de piroclastos, relativamente poco consolidados que recubre todo esta topografía suavizada.

\section{Campo de piroclastos}

Unidad geomórfica que recubre gran parte del flanco sur y oeste del volcán Barva. Litológicamente se compone de tobas cineríticas, tobas arcillosas, transición de toba a suelo y lapi1li. El trabajo de campo mostró dos secuencias bien diferenciables de piroclastos: 1) piroclastos basales y 2 ) piroclastos superiores.

Los piroclastos basales, más antiguos, tienden a ser relativamente consolidados y localmente duros, con espesores máximos de $15 \mathrm{~m}$ (Alfaro, 2003; Vargas, 2003). Se las encuentra hacia el sur por ejemplo, sobre ellos, se han construido la ciudad de Heredia y otros poblados.

Los piroclastos superiores son inconsolidados y sus espesores son irregulares y pueden llegar hasta $8 \mathrm{~m}$. Ambas secuencias están separadas por una capa guía de lapilli fino a grueso, por lo general inconsolidado (Barahona, 2003; Rojas, 2003). Los piroclastos recubren prácticamente la totalidad de las litologías infrayacentes, esto es, lavas intercaladas con piroclastos más antiguos, las cuales solo afloran por erosión en los cauces de los ríos.

El Campo de Piroclastos (Fig. 1b) está formado por laderas denudacionales de pendiente entre muy suave a suave $\left(0^{\circ}-5^{\circ}\right)$ y moderadas $\left(5^{\circ}-30^{\circ}\right)$. En general presentan una topografía suavizada y regular, presentando en algunos casos reptación moderada a fuerte y deslizamientos de suelo tipo rotacional. Además, las laderas se encuentran alineadas en dirección norestesuroeste. Presentan localmente, un patrón de drenaje desde paralelo a dendrítico, lo cual corrobora la uniformidad del material, así como la baja capacidad de infiltración en esta unidad. Las laderas de menor pendiente, por lo común, corresponden con los piroclastos de caída más recientes. Laderas y colinas muy suavizadas e incluso redondeadas se observan comúnmente sobre el Campo de Lavas. Aquí se forman depresiones propicias para la formación de pequeños lagos efímeros (área del Campo de Lavas), formados en épocas lluviosas fuertes. Los materiales que se observan en el campo son principalmente tobas, lapilli y una transición de toba a suelo los cuales sobreyacen al Campo de Lavas.

Las laderas de pendiente moderada $\left(5^{\circ}-30^{\circ}\right)$, son formas denudacionales con rasgos generalmente elongados, que se ubican en la parte central oeste y sur del área de estudio. Son producto de un aumento en la intensidad de erosión (deslizamientos) y meteorización y se encuentran ligados a alguna geoforma preexistente, como escarpes formados por frentes de coladas.

Las pendientes aumentan fuertemente hacia los cauces de los ríos produciendo deslizamientos de suelo (Alfaro, 2003; Vargas, 2003).

En está unidad la escorrentía superficial se intensifica y la poca permeabilidad de los materiales y las pendientes de las laderas ocasionan que la cantidad de agua infiltrada sea mínima. De este modo, las formas resultantes del terreno son producto de la inestabilidad de los materiales y la fuerte erosión. Alfaro (2003) logró medir una tasa de erosión máxima visible de $9 \mathrm{~cm}$ al año, lo cual se evidencia en una profundización rápida de las áreas sin cobertura vegetal, por ejemplo, caminos sin cunetas. 


\section{Campo de Lavas}

Su morfología está representada por una herradura abierta hacia el sur. Presenta en su centro pendientes entre $0^{\circ}$ y $10^{\circ}$ grados, aumentando significativamente hacia los caños fluviales, los cuales tienden a ser poco profundos. La geoforma esta cubierta por una delgada capa de piroclastos de caída, los cuales dejan ver afloramientos discontinuos de las lavas. Los frentes de coladas producen rasgos topográficos escalonados típicos. Es normal observar afloramientos en forma de cerros redondeados blocosos.

La composición de las lavas varía de basaltos a andesítas, frecuentemente vesiculares. Las vesículas pueden ser irregulares de hasta $5 \mathrm{~cm}$ de largo y abarcar hasta un 30\% del volumen de la roca (Barahona, 2003, Rojas, 2003). Las rocas de color gris claro a gris oscuro en superficie sana, por lo general porfiríticas, con fenocristales idiomórficos de feldespatos $(0,5 \mathrm{~cm}$ de diámetro) y piroxenos ocasionales, localmente en forma de prismas de enfriamiento. El espesor de estas coladas llegan hasta un máximo visible de $35 \mathrm{~m}$. Es frecuente observar autobrechas superiores y basales de hasta 1,5 $\mathrm{m}$ de espesor y acumulaciones discontinuas de bloques de lava (Barahona, 2003; Rojas, 2003).

De acuerdo con la cartografía geológica, la distribución de estas coladas es amplia, ya que se pueden encontrar en gran parte del sector sursureste del área.

\section{Falla Alajuela}

La Falla Alajuela es un rasgo geomórfico que representa un escarpe de "falla inversa-pliegue". La falla inversa es profunda y no rompe en superficie, pero produce un pliegue anticlinal asimétrico de propagación y, precisamente es este pliegue, quien produce el escarpe.

La estructura principal se compone de un anticlinal asimétrico cuyo flanco sur presenta una pendiente muy fuerte, buzante hacia el sur. El flanco norte tiene una pendiente más suave y ligeramente inclinada hacia el norte. Este flanco puede tener asociado un sinclinal trasero.
La geoforma se caracteriza por presentar una alineación en forma de herradura abierta hacia el sur y su altura topográfica llega a los $140 \mathrm{~m}$. Se encuentra disectado por algunas quebradas y ríos con orientaciones noreste-suroeste, por ejemplo, ríos Caracha, Tambor, Alajuela y Ciruelas.

Sus laderas son de pendiente fuerte, en muchos casos arriba de los $20^{\circ}$, lo cual deja cañones fluviatiles profundísimos, como por ejemplo en los ríos Itiquís y Ciruelas. En las laderas de esos cañones, se pueden encontrar depósitos coluviales y depósitos asociados posiblemente con antiguos deslizamientos. Regionalmente, esta es una de las estructuras tectónicas más importantes del Valle Central. Se extiende desde Grecia hasta Santa Bárbara de Heredia, y atraviesa el flanco sur de los volcanes Poás y Barva, limitando al sur con el Valle Central (Montero, 2000) Puede presentar un ancho de 1 a $2 \mathrm{~km}$ y una longitud de aproximadamente 24,5 km (Mora, 1995).

\section{Laderas Denudacionales de Topografía Abrupta y Escarpada}

Este mega-rasgo se observa hacia el este y sureste-este de los cráteres del volcán Barba. Los rasgos topográficos, se encuentran cubiertos por una densa selva con bosque primario (Reserva Forestal Cordillera Volcánica Central) y por una topografía muy escarpada, con alturas que van desde los $900 \mathrm{~m}$ hasta los 2500 m.s.n.m.. Son frecuentes los taludes verticales a subverticales. La comprobación de campo se realizó solo a lo largo de la carretera que atraviesa el Parque Braulio Carrillo de San José hasta Guápiles.

Los siguientes subrasgos son notorios:

\section{Patrón de drenaje}

Patrón radial, con profundos cañones fluviatiles, lo cual sugiere una topografía muy erosionada y probablemente antigua. Los ríos principales que drenan esta región son Patria, Nuevo y General. 


\section{Laderas denudacionales de topografía abrupta}

Esta geoforma tiene forma de herradura abierta hacia el este y está bordeada por un escarpe de perímetro irregular, el cual tiene alturas de hasta $300 \mathrm{~m}$. Este rasgo representa una topografía erosionada y disectada y una influencia relativamente baja o ausente de los piroclastos recientes emitidos por el volcán Barva. Hacia el sur se puede observar, un borde escarpado (observable desde San José), en donde se destacan los cerros Chompipe (extremo oeste), Tibás, Turú, Caricias, Zurquí y Hondura (extremo este) y en la parte central el cerro Achiotillal (Fig. 1a y b). No se descarta la presenscia de estructuras caldéricas antiguas (Soto 1994, Pérez 2000).

Litológicamente, se compone de basaltos con olivino, andesítas basálticas y andesitas y localmente con textura afírica. Las intercalaciones de lavas y piroclastos son comúnes. Alvarado (2000) indica que en los cortes de carretera hacia Guápiles afloran hasta 5 flujos de lava superpuestos separados por piroclastos o autobrechas.

\section{Laderas denudacionales de depósitos de avalancha}

Conforma una topografía abrupta, pero sus laderas estan ligeramente suavizadas. Tiene forma de herradura abierta hacia el este a partir de los cráteres del volcán Barva. Los colectores principales han erosionado la estructura y se han dispuesto paralelamente. Los ríos Nuevo, Patria, Calderón Muñoz, deben ser relativamente jóvenes ya que sus cauces no son tan profundos y escarpados como los observados hacia el sureste.

El Campo de Piroclastos se extiende hacia el este formando una cuña entre las laderas de los Depósitos de avalancha y las laderas denudacionales de topografía abrupta (Fig. 1a y b). Esta misma situación ocurre hacia el lado norte de volcán Barva. Se observa claramente, como este anfiteatro corta abruptamente el Campo de Piroclastos, dejando una depresión en forma de herradura (de al menos $3 \mathrm{~km}$ en su parte más ancha), constituida por bordes escarpados de hasta 200 m de desnivel. Este rasgo geomórfico presenta su ápice ubicado en el actual cráter del volcán Barva. La base de esta herradura presenta laderas de topografía irregular suavizada (debido a la escala) y con un patrón de drenaje paralelo relativamente joven. La geomorfología sugiere que este rasgo fue formado por un depósito de avalancha (debris avalanche), aunque se requiere la comprobación de campo y el estudio de los depósitos,

\section{Cráteres del volcán Barva}

Los cráteres del volcán Barva (apenas notorios en este modelo, Fig. 1a y b), fueron descritos entre otros por Protti (1986), Soto (1994), Alvarado (2000) y más recientemente Brenes, (2003), como cráteres cuspidales al macizo, en donde fluyeron múltiples coladas de lava andesítica y en forma radial a la cima. Coladas de lava fluyeron también de sus laderas, a partir de conos parasíticos (Colada Los Angeles). El Cerro Guararí, ubicado hacia el oeste, es un antiguo cono piroclástico abierto hacia el suroeste desde donde fluyeron coladas de lava (Soto, 1994; Alfaro, 2003).

\section{Laderas denudacionales del volcán Poás}

Observables en el extremo noroeste de la figura 1a y b, conformadas por un patrón de drenaje radial. El estudio de campo muestra que están formadas por piroclastos de caída que recubren ligeramente coladas de lava de composición andesítica-basáltica con estructura masiva y fluidal. Estas coladas muestran pliegues y estructuras de cizalle interno que indican que durante su efusión, estas lavas eran muy fluidas. Macroscópicamente presentan un color que varía de gris claro a oscuro (al aumentar al contenido de vidrio) en las superficies sanas y tonos naranja a morado en las pátinas de meteorización. Presentan una textura afírica fluidal con muy pocos cristales milimétricos de plagioclasa y piroxenos dispersos en una matriz vítrea. 


\section{CONCLUSIONES}

Los principales megarasgos observables son: Laderas denudacionales de topografía suavizada y laderas denudacionales de topografía abrupta. Dentro de los subrasgos más destacables son la Falla de Alajuela, así como topografías en forma de herradura que sugieren un debris avalanche así como el campo de lavas.

A partir de la modelación topográfica es posible determinar rasgos que son poco notorios en los mapas topográficos y en el campo. Para el caso del volcán Barva, los mega-rasgos geomórficos descritos anteriormente, reflejan claramente la superficie del terreno.

\section{AGRADECIMIENTOS}

Se agradece a la Vicerrectoría de Investigación, UCR, por los fondos otorgados al proyecto No. 113-A3-834: "Elaboración de un mapa geológico de un área de $84 \mathrm{~km}^{2}$ del volcán Barva, San José". A los revisores anónimos del manuscrito.

\section{REFERENCIAS}

ALFARO, R, 2003: Geología de la región suroeste del cerro Guararí. San José, CR.-Escuela de Geología, UCR. 83 págs. Univ. de Costa Rica, San José [Inf. Campaña Geol.].

ALVARADO, G. E., 2000: Volcanes de Costa Rica: Geología, historia y riqueza natural. - 284 págs. EUNED, San José.
BARAHONA, D., 2003: Estudio geológico de los alrededores del volcán Barva (Flanco S-SE). San José, CR. 125 págs. Univ. de Costa Rica, San José [Inf. Campaña Geol.].

BRENES, J., 2003: Geología y peligros volcánicos del flanco oeste y suroeste del volcán Barva, Costa Rica. - 83 págs. Univ. de Costa Rica. San José [Tesis Lic.].

MONTERO, W., 2000: Sismología y neotectónica. En: DENYER, P. \& KUSSMAUL, S. (comp.): Geología de Costa Rica. - 520 págs. Ed. Tecnológica de Costa Rica, Cartago.

MORA, M., 1995: Estudio geológico de un sector de sureste de Grecia. Provincia de Alajuela, Costa Rica. - 107 págs. Univ. de Costa Rica. San José [Inf. Campaña Geol.]

PEREZ, W., 2000: Vulcanología y petroquímica del evento ignimbrítico del Pleistoceno Medio (0.33 Ma) del Valle Central de Costa Rica. - 170 págs. Univ. de Costa Rica. San José. [Tesis Lic.].

PROTTI, R., 1986: Geología del flanco sur del volcán Barva, Heredia, Costa Rica. - Bol. Volcanol. Univ. Nac. 17: 23-31.

SOTO, G., 1994: Volcanología física. En: DENYER, P. \& KUSSMAUL, S. (comps.): Atlas Geológico. Gran Area Metropolitana. - Ed. Tecnológica de Costa Rica: 131-146

ROJAS, J., 2003: Estudio geológico integrado del sector sur del Roble, Heredia, Costa Rica. San José, CR. - 60 págs. Univ. de Costa Rica, San José [Inf. Campaña Geol.].

VARGAS, C., 2003: Geología integral del flanco SW del volcán Barva, (Carrizal, El Roble y alrededores). San José, CR. - 102 págs. Univ. de Costa Rica, San José [Inf. Campaña Geol.]. 